\title{
A relação teoria e prática esboçada na estrutura curricular do Curso de Licenciatura em Ciências Biológicas da Universidade Federal do Amapá
}

\section{Everson dos Santos David ${ }^{1}$ e Izabel Lucia dos Santos Oliveira ${ }^{2}$}

\footnotetext{
1 Pós-graduado em Gestão e Docência do Ensino Superior pela Faculdade de Teologia e Ciências Humanas/FATECH/AP. Licenciado em Ciências Biológicas pela Faculdade de Macapá/FAMA/AP e Bacharel em Ciências Biológicas pela Universidade Federal do Amapá/UNIFAP, Brasil.

E-mail: everson.david@hotmail.com 9 http://lattes.cnpq.br/1991828425569953
}

2 Mestre em Ciência da Educação/UE/Évora, Especialista em Metodologia da Educação Especial/UEPA, graduada em Pedagogia/UFPA. Professora de Didática da Secretaria Estadual de Educação/SEED/AP. Pedagoga atuando no Núcleo de Tecnologia Educacional na Secretaria Municipal de Educação/NTM/SEMED/AP. Professora do Colegiado de Pós-Graduação da Faculdade de Teologia e Ciências Humanas/FATECH/AP, Brasil.

E-mail: izabel_lucia@hotmail.com 9 http://lattes.cnpq.br/4839223290483328

RESUMO: O artigo analisou a estrutura curricular do Curso de Licenciatura Plena em Ciências Biológicas da Universidade Federal do Amapá, no que concerne a relação de unidade entre os conhecimentos teóricos e práticos, uma vez que no ensino de biologia deve se valorizar esta relação recíproca, que tem o dever de se apresentar de maneira clara e coerente, contribuindo na formação dos futuros professores de biologia. A abordagem qualitativa direcionou a pesquisa bibliográfica e documental. O resultado desta análise é satisfatória, pois se pode constatar elementos que atendem a legislação, como a lista das disciplinas obrigatórias do campo pedagógico, das disciplinas específicas e das atividades complementares, respeitando a carga horária proposta. Sendo assim, é possível concluir que a composição da estrutura curricular deve focalizar na unidade teoria e prática mediante as disciplinas de práticas de ensino e dos estágios supervisionado para fomentar a formação acadêmica e profissional, a fim de atender as com qualidade e compromisso ao mercado de trabalho e aos anseios da sociedade.

Palavras-chave: Teoria e Prática. Currículo. Biologia.

The relation theoretical and practical outline of the curricular structure of the biology science graduation of the Federal University of Amapá

ABSTRACT: This article has analyzed the curricular structure of the Full Degree Course in Biological Sciences of the Federal University of Amapá regarding the relation of unity between theoretical and practical knowledge, since in biology teaching this reciprocal relationship must be valued, which it has the duty to present itself in a clear and coherent way, contributing to the training of future biology teachers. The qualitative approach guided bibliographical and documentary research. The result of this analysis is satisfactory, since it is possible to verify elements that comply with the legislation, such as the list of compulsory subjects in the pedagogical field, the specific subjects and complementary activities, respecting the proposed timetable. Thus, it is possible to conclude that the composition of the curricular structure should focus on the unit theory and practice through the disciplines of teaching practices and supervised internships to foster academic and professional education, in order to meet to with quality and commitment the job market and the yearnings of society.

Keywords: Theory and practice. Curriculum. Biology. 


\section{INTRODUÇÃO}

Atualmente as universidades brasileiras possuem um papel categórico no enfrentamento das complexas questões instituídas para a formação dos profissionais da educação, que devem atender as demandas das disposições da Lei de Diretrizes e Bases da Educação (9394/96), do Projeto Lei no $8.035 / 2010$ que aprova o Plano Nacional de Educação (2011-2020) e das novas Diretrizes Curriculares Nacionais para Formação Inicial e Continuada dos Profissionais da Educação Básica (06/2015), que vem passando por um processo de reestruturação curricular, a partir de uma base comum nacional concebida como um eixo articulador na formação teórica e prática dos profissionais da educação que atuam no ensino fundamental e médio.

A formação dos profissionais da educação nos Cursos de Licenciatura Plena em Ciências Biológicas amplia a discussão e a reflexão, na superação da visão dicotômica existente entre teoria e prática na estrutura curricular deste curso, relação esta abordada por vários autores, tais como: Candau, Lelis, Pimenta e outros com o propósito de elaborar novos saberes defendidos pelos diferentes discursos científico-pedagógicos que constituem a identidade profissional do professor (WEISSMANN, 1998).

Ao adentrar no campo das Ciências Biológicas, é esclarecedor à importância da relação recíproca da teoria e prática, que em muitas vezes prevalece à teoria como referência para a metodologia de ensino, desprezando de maneira brusca a relevância da prática para o processo ensino aprendizagem. A biologia por apresentar uma riqueza incomensurável de conteúdos aplicáveis em todas as etapas do ensino, proporciona uma variada gama de opções no que tange à aplicação de metodologias. Daí a importância de se verificar a metodologia utilizada no ensino superior contida no Projeto Político Pedagógico, visando constatar, se o mesmo valoriza a relação teoria e prática.

Neste sentido, este artigo busca investigar com maior consistência e persistência sobre a seguinte problemática: "a estrutura curricular do curso de Licenciatura em Ciências Biológicas da Universidade Federal do Amapá, apresenta uma relação ou unidade entre teoria e prática?", pois se devem considerar as bases curriculares como eixo norteadores de uma sólida formação teórica e prática nas áreas específicas do conhecimento científico do profissional da educação.

É valido salientar, que a estrutura curricular do curso de Licenciatura Plena em Ciências Biológicas da UNIFAP, é dividida em disciplinas obrigatórias pedagógicas, disciplinas obrigatórias especificas e de atividades complementares, e atendem as exigências dos Parâmetros Curriculares do Curso de Ciências Biológicas. E é relevante realizar uma análise da relação entre teoria e pratica como parte integrante das metodologias aplicadas nas disciplinas ministradas no ensino superior no Curso de Ciências Biológicas, na reciprocidade da teoria atendida com a prática experimental e se a prática estabelece integração com a teoria, para compor a sua estrutura curricular.

O referido artigo tratou de levantar uma problemática presente em diversas áreas do conhecimento, que não é permitida nas áreas das ciências biológicas, porém é comum. Devido ao seu caráter experimental, é importante estabelecer uma relação teoria e prática, na estrutura curricular, que 
respeite integralmente as normas das diretrizes curriculares, atribuindo assim mecanismos pedagógicos na formação de profissionais competentes.

Assim, o objetivo deste trabalho é analisar a estrutura curricular do Curso de Licenciatura Plena em Ciências Biológicas da Universidade Federal do Amapá, no que concerne a relação de unidade entre os conhecimentos teóricos e práticos, por constituírem um eixo de sustentação da matriz curricular deste curso.

\section{FUNDAMENTAÇÃO TEÓRICA}

Estabelecer uma relação entre teoria e prática nem sempre é fácil, e é perceptível quando se tem um olhar desfragmentado de um todo, e ambas necessitam estabelecer uma harmoniosa relação para uma fundamentar a outra, e a outra confirmar e comprovar o que se indagou. Neste âmbito é o que moveu a história da humanidade, das ideias, dos grandes avanços industriais, das tecnologias de comunicação e transportes, movidos por ambições e questionamentos, o homem traçou um percurso dinâmico para construir suas ideias, tendo de posse a teoria e prática (RAMALHO, 2003).

Logo faz-se necessário uma compreensão da definição da etimologia das palavras, para melhor esclarecer a sua relevância na área educacional. Assim, ambos os termos são de origem grega, cujo o termo teoria faz alusão ao sentido de observação, contemplação e reflexão. Sendo próprio daquele que estuda que ler e busca nas fontes o conhecimento, para constatar, construir ou prosseguir no raciocínio de uma ideia, é o discurso fundamentado em outros discursos, porém contestável na busca da comprovação (BARBOSA, 2014).
E a prática se incube de executar, realizar, de fazer, cumprir, e é assim, que quanto o termo "prática", derivada do grego "praxis", "práxeos" se atribui o sentido de ação, e a ação Inter humana racional, porém se diferencia da "póiesis" que se é atribuída a ação produtiva e ao exercício comercial. O agir consciente sabedor do caminho a percorrer, da confirmação de seus alicerces, tudo a partir de um comando (CANDAU; LELIS, 2005).

Há muitas formas de conceber a relação teoria e prática, mas serão destacadas duas visões: a dicotômica e a de unidade. Nesta forma de estabelecer a teoria e prática, é totalmente distinta uma da outra, não existe nem uma relação, a sua oposição carrega uma contrariedade uma com a outra, estabelecendo assim uma incoerência, aos teóricos basta apenas pensar, refletir, observar, e aos adeptos a prática, a executar, agir, fazer, seria dentro da visão dicotômica, uma visão dissociativa de conceber teoria e prática (CANDAU; LELIS, 2005).

Outra visão dicotômica é a visão associativa, nesta visão seria inviável uma relação, ou seja, é desta forma que muitas vezes profissionais agem, vivenciando apenas o que lhe convém, esta é a dificuldade relatada por muitos discentes, ao descrever as suas principais dificuldades, ao assimilar o que está sendo transmitido, que muitas vezes é dissociado e distorcido na transmissão, é o que se deveria ser levado em conta, o caminho percorrido pelo discente, das suas habilidades que não foram aprimoradas para a interpretação textual ou para a criticidade, tende atrofiar o desenvolvimento acadêmico (RAMALHO, 2003).

Para Candau e Lelis (2005), a outra forma de estabelecer a relação teoria e prática é a visão de unidade, esta visão se apresenta 
mais viável para execução de metodologias satisfatórias ao processo ensino aprendizagem, pois a unidade na relação teoria e prática são estabelecidas em relações de reciprocidade, que garantem uma relação dependente. A prática precisa da teoria para se firmar em seus aspectos concretos, e assim a teoria necessita da comprovação da prática para sair do abstrato, e neste meio a ciência se estabelece como conhecimento construtivo, a partir que ela experimenta, testa e verifica em sua praticidade uma teoria pensada, refletida e criticada, em um âmbito primordial para a sua atuação.

Nestas perspectivas pode se realizar um paralelo quanto à importância da relação teoria e prática na Estrutura Curricular do curso de Licenciatura Plena em Ciências Biológicas, sendo que esta relação se faz presente em diversas áreas do conhecimento, no entanto, é relevante destacar a área das ciências biológicas, a sua magnitude para o diferencial na formação dos futuros professores e biólogos. É bom destacar que a fundamentação da biologia é o de contribuir diretamente para a compreensão e das transformações do mundo, designando ao homem o papel participe e integrador do universo (ALQUINI; SAMPAIO, 2001).

Desta forma, a estrutura curricular do Curso de Licenciatura Plena em Ciências biológicas é diversificada quanto as suas disciplinas, que atendem com dinamismo os conteúdos a serem lecionados em sala de aula, sabe-se que a assimilação dos conteúdos é algo bastante discutível no âmbito do ensino por representar a prova real que pode respaldar ou descartar uma metodologia qualquer, de acordo com a sua eficácia. Porém é certeiro o sucesso de uma metodologia que visa confirmar a assimilação da teoria com a eficácia da prática (RAMA-
LHO, 2003).

Em se tratando da regionalidade no ambiente onde cada indivíduo está inserido são várias as vezes que a prática é descartada, com as diversas justificativas, pela exigência curricular de conteúdo, que tem como estudo objetos e indivíduos não comuns em especificas regiões, ou pelo alto custo de equipamentos e falta de investimentos de aulas de campo, situações contraditórias quando se entende que o conhecimento científico exige coerência, um contato direto com seu objeto de estudo (ALQUINI; SAMPAIO, 2001).

Diante do que é exposto sobre a relação entre teoria e pratica no ensino de ciências biológicas se estabelece uma relação mútua para a dinâmica do conhecimento científico, a teoria se apresenta de maneira imaginária, no ponto de vista daquele que está tendo o primeiro contato, porém a interação com a prática completa o conhecimento já refletido e discutido, que agora será experimentado.

Esta importância é ressaltada logo abaixo por Alquini e Sampaio (2001 p.178):

É de grande relevância da observação e compreensão do mundo em que vivemos. Isso é justificado, porque o acesso ao conhecimento científico, histórico e socialmente acumulado parte dos fatos concretos da prática social e das diversas formas objetivas e dinâmicas da natureza, em um movimento de compreensão das concatenações existentes entre elas. Estas, uma vez descobertas, são demonstradas, por via experimental, até onde seja possível.

Observa-se, que quando se trata das $\mathrm{Ci}$ ências Biológicas, há a dificuldade de interagir os conhecimentos científicos com os conhecimentos do cotidiano, apresentando 
a ideia de que biologia é difícil, com muitos nomes científicos para decorar, tornando conteúdos relativamente simples, se trabaIhados na prática, em assunto de grande complexidade do ponto de vista teórico. Desta forma o aluno cria uma barreira entre ele e o conhecimento, devido à metodologia de apresentar apenas de forma teórica e não respeitando o experimental (MEDEIROS et al., 2017).

Em vista de conhecimentos anteriores, é que se firmará a biologia com objetivo de propor ao aluno, uma profunda reflexão a respeito de vários problemas sociais. É nesta realidade que se encontra hoje o profissional de Licenciatura de Ciências Biológicas, na responsabilidade de resgatar e propor em sua didática esta relação teoria e prática, como meio de valorização, sem deixar de ter um olhar audacioso, e de ir em busca de explicações exatas para a vida (BARBOSA, 2014).

A partir destas dificuldades é que está respaldada a construção de um bom Projeto Político pedagógico, que em ciências biológicas é incoerente a dicotomia entre teoria e pratica, sendo mais viável um olhar cuidadoso para a criação de um projeto que atenda de maneira geral a relação teoria e pratica, para corresponder objetivamente o caráter experimental desta tão importante ciência (ALQUINI; SAMPAIO, 2001).

\section{METODOLOGIA}

A Fundação Universidade Federal do Amapá - UNIFAP é uma Instituição de Ensino Superior Pública de direito privado, criada pela Lei n. 7.530, de 29 de agosto de 1986, e instalada pelo decreto n. 98.977, de 02 de março de 1990, vinculada ao Ministério da Educação, com sede na cidade de
Macapá, Estado do Amapá.

A criação do Curso de Ciências Biológicas - Licenciatura e Bacharelado - ocorreu com o Parecer no. 107/69 do CFE e oficializado com da Portaria da Reitoria № 015 de 03/11/1998. A sua implantação ocorreu no ano 2000 no turno Matutino/Vespertino. Reconhecido em 03 de maio de 2007 pela Portaria SESu/MEC no 376, com oferta de 25 vagas anuais para licenciatura (UNIFAP, 2008).

A distinta pesquisa buscou no método qualitativo encontrar evidências quanto à problemática estudada, para assim traçar resultados coerentes com a real proposta para o ensino, pesquisa e extensão, ao analisar o Projeto Político Pedagógico do Curso de Licenciatura Plena em Ciências Biológicas da Universidade Federal do Amapá, dando referência a proposta para o aprendizado.

O Curso de Ciências Biológicas da Universidade Federal do Amapá (UNIFAP) é dividido nas modalidades de Licenciatura e Bacharelado, tendo como ênfase a biologia geral. Em 2008, foi elaborado um único projeto político pedagógico para atender as duas modalidades, e em 2014 para atender as necessidades da modalidade de bacharelado, se construiu um projeto especifico para esta modalidade (UNIFAP, 2008).

É necessário realizar uma análise do Projeto Político Pedagógico de 2008, projeto que atende a modalidade Licenciatura que ainda está em vigor no colegiado do curso. Uma vez que a Licenciatura trabalha diretamente na formação dos futuros professores, o projeto não se limita apenas em preparar para a docência, mas procura inserir os alunos na pesquisa, distribuídos segundo a linha de pesquisa presente no curso, no qual os acadêmicos mais se identificam.

O enfoque principal foi a análise da es- 
trutura curricular contida no Projeto Político Pedagógico do curso de Licenciatura Plena em Ciências Biológicas da UNIFAP, que realizou se através de um roteiro que a princípio exigiu uma leitura rígida para a percepção da proposta curricular na integração de teoria e prática. Em seguida, a estrutura curricular foi confrontada com outros documentos importantes para a educação brasileira, como a Lei de Diretrizes e Bases da Educação Nacional: no 9394/96, o parecer do Conselho Federal de Biologia № 01/2010, as Diretrizes Curriculares para os cursos de Ciências Biológicas, as Diretrizes Curriculares Nacionais para a Formação Inicial e Continuada dos Profissionais do Magistério da Educação Básica e os teóricos da educação (UNIFAP, 2014).

0 referido artigo basear-se em pesquisas bibliográficas, para dá suporte e base firme coesa para o pensamento transcrito no decorrer do trabalho, foram consultadas obras literárias da biblioteca da Universidade Federal do Amapá, e de artigos científicos consultados em meio virtual no Google Acadêmico, com a perspectiva de se analisar, entender e registrar a proposta para a qualidade do ensino no nível superior equivalente ao curso de ciências biológicas, tendo o objeto de estudo a relação entre teoria e prática apresentada no Projeto Político Pedagógico do curso de ciências biológicas da Universidade Federal do Amapá.

O método qualitativo não se preocupa em resultados numéricos, mas deixa aberto um leque de interpretações para uma análise indutiva, que tem a incumbência do rigor, e de ser criterioso quanto às informações que se busca, para a compreensão das mesmas, ou seja, o foco é a compreensão do contexto, para a interpretação dos eventos. (DALFOVO; LANA; SILVEIRA, 2008)
A pesquisa documental se caracteriza pela abordagem diversificada de fontes, se confundindo muitas vezes com a pesquisa bibliográfica, no entanto, ela aborda de maneira mais minuciosa, documentos que não poderiam constar como referencial teórico. Sendo assim, o acesso a Estrutura curricular está integrada ao Projeto Político Pedagógico do curso de Licenciatura Plena em ciências biológicas, que é um documento que prevê metas para serem alcançadas, no qual se apresenta de maneira clara e objetiva, o perfil e identidade da formação que se quer propor para os futuros profissionais.

O curso também dispõe de uma página on-line para aproximar e integrar a comunidade, assim como divulgar os trabalhos e produções dos alunos do curso. Foi através deste meio que se foi possível o acesso ao Projeto Político Pedagógico do curso, de possível acessibilidade neste endereço eletrônico (www.unifap.br/biologia).

\section{RESULTADOS E DISCUSSÃO}

O Projeto Político Pedagógico do curso de licenciatura plena em ciências biológicas da UNIFAP se incube de traçar caminhos coerentes com as necessidades acadêmicas, atendendo as exigências atuais de formar profissionais dinâmicos conscientes do seu papel social, do despertar para a pesquisa científica, atribuindo aos discentes habilidades e competências que visem a construção do conhecimento (BRASIL, 2010).

A Estrutura Curricular apresentada no Projeto Político Pedagógico do Curso de Licenciatura Plena em Ciências Biológicas da UNIFAP (2008), destaca-se que as atividades acadêmicas são compostas por estratégias que tendem a destacar a indissolubili- 
dade do ensino, pesquisa e extensão, tripé que rege e garante a qualidade das Universidades. Valorizar o princípio de indissolubilidade é manter com integridade a percepção acadêmica de um ensino que se responsabiliza formar profissionais completos para atender as mazelas sociais.

$\mathrm{Na}$ estrutura curricular do curso de Licenciatura Plena em Ciências Biológicas da UNIFAP, não fica evidente a unidade da relação teoria e prática, porém o Projeto Político Pedagógico engloba as ementas das disciplinas, onde contem pontos esclarecedores desta relação. Na estrutura curricular apresenta disciplinas que variam em uma carga horária de $60 \mathrm{~h}$ a $120 \mathrm{~h}$, sendo que nas ementas das disciplinas são divididas em teórica e pratica, assim como a forma metodológica e da avaliação no decorrer do processo (UNIFAP, 2014).

Ao verificar outros Cursos de Biologia das Instituições de Ensino Superior da região Norte, observa se na Estrutura Curricular do Curso de Licenciatura Plena em Ciências Biológicas da Universidade Federal do Amazonas. Assim, a preferência em deixar bem visível a divisão de créditos e da carga horária teórica e prática, com a finalidade de garantir para seus discentes no decorrer do processo uma formação sólida, que se respalda na unidade de teoria e prática, ou seja, através dos créditos se exige do aluno um domínio da teoria e a aplicabilidade de suas competências na prática, podendo levar o discente a retenção no caso do baixo rendimento seja na parte teórica ou na prática (UFAM, 2003).

A estrutura curricular do Curso de Licenciatura Plena em Ciências Biológicas não apresenta um encadeamento entre as disciplinas, ou seja, não se exigem disciplinas pré-requisitos para cursar outras disciplinas, porém ocorre a interdisciplinaridade nos conteúdos, e o cumprimento de um caminho crítico da estrutura curricular, que seja orientado por uma sequência lógica dos conteúdos, a fim de contribuir satisfatoriamente com o processo (UNIFAP, 2014).

Sendo assim, o Projeto Pedagógico ao descrever a estrutura curricular do curso de Ciências biológicas, faz referências ao cumprimento minucioso aos parâmetros curriculares dos cursos de ciências biológicas, propondo meios de formação para um perfil satisfatório de seus discentes, na interdisciplinaridade dos conteúdos a serem mencionados na estrutura curricular e nas ementas de ensino. Percorrendo um caminho crítico que corresponda a uma lógica que vise cada disciplina basear-se umas às outras (UNIFAP, 2014).

O Conselho Federal de Biologia também contribui com o seu parecer CFBio № 01/2010, Brasil (2010) define o licenciado em ciências biológicas como um autêntico biólogo, atribuindo as suas funções plenas no campo da educação, da sua participação direta na formação de cidadãos conscientes com o seu papel na sociedade, assim como a mobilização para os temas ambientais e de saúde pública, dotado de conhecimentos atribuídos a sua formação técnica e pedagógicas para conduzir todo o processo educativo.

Há o cumprimento de uma carga horária de 4.180 horas na matriz curricular do curso de licenciatura plena de Ciências Biológicas da UNIFAP, atendendo as diretrizes curriculares dos cursos de licenciatura plena em ciências biológicas, estas apresentadas nas resoluções № 001 de 18/02/2002 e no 002 de 19/02/2002 do Conselho Nacional de Educação, estipulam uma carga horária mínima de 2.800 horas aula para a sua inte- 
gralização, que atendam a relação teoria e prática distribuída em disciplinas pedagógicas, especificas e de atividades complementares. A tabela logo abaixo indica a divisão da carga horária (UNIFAP, 2014).

Tabela 1 - Divisão da carga horária do curso de Licenciatura Plena em Ciências Biológicas da UNIFAP.

Table 1 - Division of the timetable of the course of Full Degree in Biological Sciences of UNIFAP.

\begin{tabular}{|l|l|}
\hline DISCIPLINAS & $\mathrm{CH}$ \\
\hline Obrigatórias Específicas & 2.670 \\
\hline Obrigatórias Pedagógicas & 1.310 \\
\hline Atividades complementares & 200 \\
\hline Total & $\mathbf{4 . 1 8 0}$ \\
\hline
\end{tabular}

Fonte: UNIFAP (2008).

A carga horária do Curso de Licenciatura Plena em Ciências Biológicas da UNIFAP caminha junto com a tendência dos cursos das Instituições de Ensino Superior da região Norte, como o curso Licenciatura Plena em Ciências Biológicas da Universidade Federal do Amazonas, UFAM (2003) que adotam uma "carga horária total para a licenciatura de 3440 horas", sem contar com as disciplinas optativas.

No curso de Licenciatura Plena em Ciências Biológicas da Universidade Federal do Pará, UFPA (2005), “a carga horária total é de 3502 horas, sendo 1.088 horas voltadas para a formação específica para os docentes". Essas cargas horárias são consideradas altas, porém as mesmas permitem dinamizar a formação acadêmica dos futuros professores, sendo primordial para a integração teoria e prática.

\subsection{Disciplinas obrigatórias pedagógicas do Curso de Licenciatura Plena em Ciências Biológicas da UNIFAP}

São compostas por uma carga horária 1.310h/aula, são disciplinas que permeiam a formação pedagógica, que preparam para uma atuação de excelência na docência, sendo fundamental para a formação dos docentes, que nas disciplinas de práticas de ensino e estágios supervisionados ganham maior destaque, sendo o momento preferencial para execução da teoria, que irá estabelecer uma relação una com a prática. Sendo assim, apresento o elenco das disciplinas pedagógicas juntamente com sua carga horária (GATTI, 2014).

Tabela 2 - Elenco das Disciplinas obrigatórias Pedagógicas e de sua carga horária no curso de Licenciatura Plena em Ciências Biológicas da UNIFAP.

Table 2 - List of Compulsory Pedagogical Disciplines and their workload in the course of Full Degree in Biological Sciences of UNIFAP.

\begin{tabular}{|c|c|c|}
\hline № & DISCIPLINAS PEDAGÓGICAS & $\mathrm{CH}$ \\
\hline 1. & Didática & 60 \\
\hline 2. & Estrut e Func. do Ens. Básico e Super. & 60 \\
\hline 3. & Sociologia da Educação & 90 \\
\hline 4. & Psicologia da Educação & 60 \\
\hline 5. & Estágio Supervisionado I e II & 210 \\
\hline 6. & Prática de Ensino & 100 \\
\hline 7. & Biologia da Educação & 60 \\
\hline 8. & Estágio Supervisionado III e IV & 210 \\
\hline 9. & Prática de Ensino II & 105 \\
\hline 10. & Met. do Ens. de Biologia e de Ciências & 120 \\
\hline 11. & Prática de Ensino III & 105 \\
\hline \multirow[t]{2}{*}{12.} & Trabalho de Conclusão de Curso & 120 \\
\hline & TOTAL & 1.310 \\
\hline
\end{tabular}

Fonte: UNIFAP (2008).

Observa se, que as disciplinas práticas de ensino I, II e III, são disciplinas que inserem o acadêmico na experiência da docência, é extremamente prática que exige dos discentes habilidades teóricas para o desenvolvimento de planos para a execução da regência e na construção de projetos para a atuação e intervenção, e na elaboração de relatórios, é composta por uma carga horária total de 400h. (UNIFAP, 2008).

As práticas pedagógicas são disciplinas divididas em três semestres, onde irão conduzir o acadêmico para uma prática crítica reflexiva, que irá inseri-lo no contato direto 
no campo de trabalho, para a execução dos conhecimentos pedagógicos e biológicos, que irão ser remetidos em ações que sensibilizem para o cenário do ensino fundamental e médio, desenvolvendo as suas competências para o processo ensino aprendizagem.

A seguir, cito as Diretrizes Curriculares Nacionais para os Cursos de Ciências Biológicas, que relevam a formação pedagógica diante dos conteúdos específicos das Ciências Biológicas.

A modalidade Licenciatura deverá contemplar, além dos conteúdos próprios das Ciências Biológicas, conteúdos nas áreas de Química, Física e da Saúde, para atender ao ensino fundamental e médio. A formação pedagógica, além de suas especificidades, deverá contemplar uma visão geral da educação e dos processos formativos dos educandos. Deverá também enfatizar a instrumentação para o ensino de Ciências no nível fundamental e para o ensino da Biologia, no nível médio. (BRASIL, 2002 p.6)

Atendendo a estas exigências, as disciplinas de estagio supervisionado I, II, III e IV, compostas por uma carga horária de 400h, divididas em dois semestres de formação acadêmica, se diferem das práticas de ensino, pois, as disciplinas de estágios integram a elaboração do Trabalho de Conclusão de Curso, mais cuja finalidade é a apresentar o mercado do trabalho, onde na qualidade de estagiário proporciona ao discente um aprendizado prático muito salutar ao seu desempenho acadêmico (VALLADÃO, 2014). Os estágios ocorrem nas escolas estaduais, a fim de proporcionar um contato direto com a modalidade de educação básica.

A Estrutura Curricular, presente no Projeto Político Pedagógico do Curso de Licenciatura Plena em Ciências Biológicas, atende explicitamente as Diretrizes Curriculares Nacionais para a Formação de Professores da Educação Básica, em nível superior, curso de licenciatura, de graduação plena. Apresentada logo abaixo:

Art. 13. Em tempo e espaço curricular específico, a coordenação da dimensão prática transcenderá o estágio e terá como finalidade promover a articulação das diferentes práticas, numa perspectiva interdisciplinar.

$\S 1$ 을 A prática será desenvolvida com ênfase nos procedimentos de observação e reflexão, visando à atuação em situações contextualizadas, com o registro dessas observações realizadas e a resolução de situações-problema.

$\S 2$ - A presença da prática profissional na formação do professor, que não prescinde da observação e ação direta, poderá ser enriquecida com tecnologias da informação, incluídos o computador e o vídeo, narrativas orais e escritas de professores, produções de alunos, situações simuladoras e estudo de casos.

§ 3 ㅇ O estágio curricular supervisionado, definido por lei, a ser realizado em escola de educação básica, e respeitado o regime de colaboração entre os sistemas de ensino, deve ser desenvolvido a partir do início da segunda metade do curso e ser avaliado conjuntamente pela escola formadora e a escola campo de estágio. (BRASIL, 2002 p.31)

A regência será a principal atividade executada, assim como o planejamento, que exigirá dos acadêmicos conhecimentos já adquiridos no decorrer da formação. Que serão compostas por disciplinas como didática geral, metodologia do ensino de ciências e biologia, biologia da educação, estrutura do funcionamento do ensino básico e superior, psicologia da educação e sociologia da educação (PIMENTA, 2012).

Estas disciplinas tendem a fundamentar toda a prática pedagógica que será executada pelo aluno, na sua preparação para a 
atuação em sala de aula, que irá constatar problemas sociais, psicológicos, e culturais, assim como atribuirá sua competência técnica no funcionamento e atribuições na educação básica, que irá inseri-lo como agente importante para o ensino (MARCHELLI, 2017).

Tais disciplinas apresentam uma relação teoria e prática, pois as mesmas exigem um contato com a teoria para orientar uma prática consciente, que se responsabilize com a sistemática educacional, que visa desenvolver no futuro professor de ciências e biologia, a sensibilidade para uma docência coerente, respeitando a realidade que o indivíduo está inserido e no seu comprometimento com a formação de autênticos cidadãos.

Segundo Pimenta (2012), a profissão de professor exige a prática como qualquer outra profissão, sendo incumbência do curso proporcionar uma ação docente, para a atuação do acadêmico, valorizando potencialidades de domínio de conteúdo, da escrita, da oralidade e de planejamento, introduzindo e apresentando no ambiente profissional, o componente essencial para o currículo do curso.

\subsection{Disciplinas obrigatórias específicas do Curso de Licenciatura Plena em Ciências Biológicas da UNIFAP}

As disciplinas obrigatórias específicas atribuem ao acadêmico de licenciatura plena em Ciências Biológicas conhecimentos técnicos científicos, tendem a preparar para atividades de cunho de pesquisas, uma vez que o licenciado também será um perpétuo pesquisador no decorrer da sua trajetória profissional. O seu conhecimento será todo voltado para o ensino, que desenvolverá habilidades de produção metodológicas para apresentar de forma sucinta e dinâmica as diversidades biológicas (UNIFAP, 2014).

As disciplinas obrigatórias específicas do Curso de Licenciatura Plena em Ciências Biológicas da UNIFAP foram organizadas seguindo uma sequência lógica que exige do discente um contato a princípio básico para o mais complexo no decorrer dos semestres, porém, não se exige pré-requisito para cursa-las, podendo o aluno antecipalas ou realizar a reposição no caso de baixo rendimento.

No Projeto Político Pedagógico do Curso de Licenciatura Plena em Ciências Biológicas Universidade Federal do Amazonas. A Estrutura Curricular é dividida em núcleos de conhecimentos, que são: Biologia celular, molecular e evolução, Diversidade biológica, Ecologia, Fundamentos de Ciências Exatas e da Terra, Fundamentos Filosóficos e Sociais, Didáticas, Prática como Componente Curricular, Estágio Supervisionado de Ensino e Atividades Acadêmico CientíficoCulturais, e inicialmente são lecionadas as disciplinas básicas de licenciatura, juntamente com o conteúdo básico de biologia, e na metade do curso iniciam os estágios supervisionados (UFAM, 2003),

A Universidade Federal do Pará, UFPA (2005), A Estrutura Curricular inova ao propor aos discentes o estágio rotatório, podendo escolher três áreas, entre elas: Biologia Celular, Biologia Molecular, Fisiologia, Biologia Animal, Museu de Zoologia, etc. contribuindo para um currículo integrado, para uma sugestão de estruturação complementar, flexível e dinâmica, incluindo em seu conteúdo os eixos temáticos.

Nas ambas as instituições já existem uma estruturação física em seus espaços e peda- 
gógica nos currículos, que permitem a transição entre os cursos do Departamento de Ciências Biológicas ou de outros, porém, na Universidade Federal do Amapá, esta transição do alunado nas disciplinas básicas e comuns entre diversos cursos ainda não é possível, implicando nesta diversificação na estrutura curricular. No entanto, a sua oferta de disciplinas específicas está de comum acordo com as distintas Instituições de Ensino Superior. A seguir apresento o elenco das disciplinas obrigatórias especificas e de sua carga horária.

Tabela 3 - Elenco das Disciplinas obrigatórias específicas e de sua carga horária no curso de Licenciatura Plena em Ciências Biológicas da UNIFAP.

Table 3 - List of specific compulsory subjects and their workload in the course of Full Degree in Biological Sciences of UNIFAP.

\begin{tabular}{|c|c|c|}
\hline $\mathrm{N}^{\circ}$ & DISCIPLINAS ESPECÍFICAS & $\mathrm{CH}$ \\
\hline 1 & Biologia Celular & 90 \\
\hline 2 & Matemática p/ as C. Biológicas. & 60 \\
\hline 3 & Química Geral & 60 \\
\hline 4 & Física Geral e Experim. & 90 \\
\hline 5 & Geologia Básica & 60 \\
\hline 6 & Metod. e Técnicas de inv. Científica & 60 \\
\hline 7 & Língua Portuguesa e Comum. & 60 \\
\hline 8 & Embriologia Comparada & 60 \\
\hline 9 & Anatomia Comparada & 120 \\
\hline 10 & Química Orgânica & 90 \\
\hline 11 & Bioestatística & 60 \\
\hline 12 & Bioquímica I e II & 120 \\
\hline 13 & Histologia Comparada & 90 \\
\hline 14 & Biofísica & 60 \\
\hline 15 & Evolução & 60 \\
\hline 16 & Físico-Química & 60 \\
\hline 17 & Botânica I e II & 180 \\
\hline 18 & Biologia Molecular & 60 \\
\hline 19 & Genética Básica & 60 \\
\hline 20 & Paleontologia & 60 \\
\hline 21 & Zoologia I, II e III & 360 \\
\hline 22 & Fisiologia Geral & 90 \\
\hline 23 & Microbiologia e Imunologia & 90 \\
\hline 24 & Parasitologia Geral & 120 \\
\hline 25 & Biogeografia & 60 \\
\hline 26 & Oceanografia e Limnologia & 60 \\
\hline 27 & Educação Ambiental & 60 \\
\hline 28 & Ecologia Geral & 120 \\
\hline \multirow[t]{2}{*}{29} & Antropologia Biológica & 60 \\
\hline & TOTAL & 2.670 \\
\hline
\end{tabular}

Fonte: UNIFAP (2008).
As relações ente teoria e prática serão primordiais para o dinamismo das disciplinas específicas, exigindo a necessidade de aulas práticas cada vez contínuas, com a diminuição progressiva de aulas expositivas, pois entende que a diversificações didáticas e pedagógicas contribuem diretamente para o processo ensino aprendizado, entusiasmando no estudante a autonomia e o compromisso com o seu próprio aprendizado (PIMENTA, 2012).

A composição das disciplinas corresponde a uma carga horária de 2.670 horas aula, divididas em 33 disciplinas compostas por 60, 90 e 120horas, estas deverão se voltar para as práticas do aluno, desenvolvida em apresentações de seminários, discussões, na condução de experimentos, na elaboração de materiais didáticos e entre outras, que poderão cativá-los para a docência, ou seja, mesmo sendo disciplinas obrigatórias específicas, as mesmas devem permitir uma atuação pedagógica do discente (UNIFAP, 2014).

Toda a sua composição curricular atende a experimentação como caráter preferencial para uma formação consolidada em técnicas, autonomia, e domínio de conteúdo, para que o aluno possa percorrer esta gama de linhas de pesquisas, esteja preparado para a atuação em sala de aula, pois este é a composição de um conhecimento que o mesmo irá transmitir e aperfeiçoar a partir das suas experiências.

\subsection{Atividades complementares}

O Projeto Político Pedagógico do curso de Ciências Biológicas atribui a estrutura curricular a expor o compromisso do colegiado com as disciplinas de Atividades Complementares Acadêmica Científicas e Cultu- 
rais I, II, III e IV, a serem desenvolvidas em 200h/aulas.

As mesmas tendem a inserir o alunado nos grupos de pesquisas e das atividades laboratoriais, propondo uma prática contínua no processo de ensino aprendizagem, adquirindo assim, competência na produção científica, assim como o incentivo de bolsas de iniciação científica oferecida pela IES. Incentivos estes que refletem nas produções científicas para diversos congressos e outro evento de natureza científica (CARNEIRO; PIPITONE, 2017).

Atendendo as Diretrizes Curriculares para os cursos de Ciências Biológicas, Brasil (2002) o Projeto Político Pedagógico do Curso de Ciências Biológicas da UNIFAP, decorre sobre trajetória acadêmica, o aluno é conduzido a consolidar a sua carreira, enriquecendo o currículo, na apresentação de Trabalhos em eventos técnico-científicos e na publicação de trabalhos em revistas científicas, poderá participar em estágios voluntário em pesquisa e extensão e das oficinas, e nos projetos multidisciplinar voltado para o ensino prático de ciências e biologia. Vale também ressaltar a adesão em outras áreas importantes para a biologia, como a informática aplicada à pesquisa em biologia e ao ensino de biologia, e a cursos de línguas estrangeiras como inglês, francês, espanhol etc.

Todas estas atividades ficam a critério do acadêmico, da sua escolha segundo a sua preferência, pois o curso na estrutura física da IES oferece na pessoa de seus docentes projetos voltados para diversas áreas da biologia, presente na a estrutura curricular que estabelece uma dinâmica relação da teoria com a prática, apreciando a pesquisa individual e coletiva, suscitando a importância dos estágios e da participação em atividades de extensão (UNIFAP, 2008).

A relação teoria e prática se demonstra claramente na estrutura curricular da licenciatura plena em Ciências Biológicas, a sua estrutura respeita fielmente as exigências das legislações dos cursos de Ciências Biológicas e do Conselho Regional de Biologia. Além de seguir um mapa crítico coerente, que tende a indagar dos discentes suas experiências no decorrer do curso, na construção de um conhecimento sustentado na relação teoria e prática, uma vez que a lógica de organização das disciplinas contribui diretamente para a eficácia do ensino, que exige em sua estrutura a indissolubilidade da teoria e prática, sendo impossível imaginar esta indissolubilidade, pois assim como a estrutura curricular, quanto o Projeto Político Pedagógico do Curso e as ementas, apontam rigorosamente para a importância desta relação (UNIFAP, 2014).

\section{CONCLUSÃO}

Foi de relevância significativa a análise da relação entre teoria e prática apresentada na estrutura curricular do curso de licenciatura plena em ciências biológicas da Universidade Federal do Amapá, com acesso projeto político pedagógico, onde a relação teoria e prática se estabelece em um cenário viável para a sua atuação, encontrando nas ciências biológicas a tarefa una, de compor o conhecimento nas teorias e na experimentação, completando a sua eficácia no ensino, esclarecendo e dando a oportunidade para um entendimento satisfatório para o prosseguimento do processo.

Ao contrário disto, é inadmissível uma relação dicotômica da teoria e prática, em uma realidade em constante avanço tecnológico, no qual se exige uma dinâmica, que 
mesmo assim, ressalta a importância do pensamento crítico e da disponibilidade para atender as problemáticas da sociedade. É neste ambiente que a estrutura curricular deve se comprometer em propor esta variedade curricular, afim de admitir uma formação consolidada e completa nas práticas pedagógicas, nos conhecimentos específicos e nas atividades extras curriculares.

$\mathrm{Na}$ estrutura curricular é possível ressalvar a importância de um planejamento que estabeleça a relação teoria e prática, na realização das atividades pedagógicas, que seja elaborado de acordo com a realidade dos alunos, segundo as suas dificuldades, e do que é essencial para a sua formação. Diante da problemática apresentada no início deste trabalho, a estrutura curricular do curso de Licenciatura Plena em Ciências Biológicas, respeita integralmente as normas das diretrizes curriculares.

Apesar de se apresentar de forma simples, porém coerente, resta saber se a proposta da relação teoria e prática, apresentada no Projeto Político Pedagógico do Curso de Licenciatura Plena em Ciências Biológicas da UNIFAP especificamente a Estrutura Curricular é colocada em prática em sala de aula, pois este trabalho vem contribuir para uma reflexão dos docentes e futuros profissionais das Ciências biológicas, para o discernimento de cada momento proposto na estrutura curricular, guiando os planos e ementas do curso, que devem ser elaborados e visto como uma oportunidade de reflexão e como uma proposta de mudança, inovação na prática pedagógica, valorizando desde o princípio a relação teoria e prática para um bom êxito da formação acadêmica.

O objetivo desta pesquisa foi alcançado ao realizar a análise da relação de unidade entre os conhecimentos teóricos e práticos, por constituírem um eixo de sustentação da matriz curricular do Curso de Licenciatura Plena em Ciências Biológicas da Universidade Federal do Amapá.

\section{REFERÊNCIAS}

BARBOSA, A. T. A Prática como Componente Curricular nos Projetos Pedagógicos dos Cursos de Licenciatura em Ciências Biológicas. X ANPED SUL, Florianópolis, p. 01-18, out., 2014.

BRASIL. Conselho Federal De Biologia - CFBio. Revisão das áreas de atuação Proposta de requisitos mínimos para o biólogo atuar em pesquisa, Projetos, análises, perícias, fiscalização, emissão de laudos, Pareceres e outros serviços nas áreas de meio ambiente, saúde e Biotecnologia. Parecer CFBio № 01/2010. Publicada no DOU, Seção 1, de 24/03/2010.

BRASIL. Conselho Nacional de Educação Câmara De Educação Superior. Diretrizes Curriculares para os cursos de Ciências Biológicas. Resolução CNE/CES 7, de 11 de março de 2002. Diário Oficial da União, Brasília, 26 de março de 2002. Seção 1, p. 12.

BRASIL. Conselho Nacional de Educação. Diretrizes Curriculares Nacionais para a Formação Inicial e Continuada dos Profissionais do Magistério da Educação Básica. Resolução CNE/CP n. 02/2015, de 1ㅇ de juIho de 2015. Brasília, Diário Oficial a República Federativa do Brasil, seção 1, n. 124, p. 8-12, 02 de julho de 2015.

BRASIL. Conselho Nacional de Educação. Diretrizes Curriculares Nacionais para a Formação de Professores da Educação Básica, em nível superior, curso de licenciatura, de graduação plena. Despacho do Ministro em 17/1/2002, publicado no Diário Oficial da União de 18/1/2002, Seção 1, p. 
31.

BRASIL. Projeto de Lei do Plano Nacional de Educação (PNE 2011/2020): projeto em tramitação no Congresso Nacional / PL no 8.035 / 2010 /. Brasília: Câmara dos Deputados, Edições Câmara, 2011. 106 p.

BRASIL. Senado Federal. Lei de Diretrizes e

Bases da Educação Nacional: no 9394/96.

Brasília: 1996.

CANDAU, V.M; LELIS, I.A. A Relação TeoriaPrática na Formação do Educador. In: CANDAU, V. M. (org). Rumo a uma Nova Didática. 16. ed. Rio de Janeiro: Vozes, 2005.

CARNEIRO, E. A.; PIPITONE, M. A. P. Análise do Projeto Pedagógico de um Curso de $\mathrm{Ci}$ ências Biológicas Face às Diretrizes Curriculares Nacionais. Rev. Ens. Educ. Cienc. Human., Londrina, v. 18, n.3, p. 285-292, 2017. CERVO, A. L.; BERVIAN, P. A.; SILVA; R. da. Metodologia cientifica. 6. ed. São Paulo: Pearson Prentice Hall, 2007.

DALFOVO, M. S.; LANA, R. A.; SILVEIRA, A. Métodos quantitativos e qualitativos: um resgate teórico. Revista Interdisciplinar Científica Aplicada, Blumenau, v. 2, n. 4, p. 01- 13, Sem. II. 2008.

GATTI, B. A. Formação Inicial de Professores para a Educação Básica: Pesquisas e Políticas Educacionais. Est. Aval. Educ., São Paulo, v. 25, n. 57, p. 24-54, jan./abr. 2014.

MARCHELLI, P. S. Da LDB 4.024/61 ao debate contemporâneo sobre as bases curriculares nacionais. Revista e-Curriculum, São Pa ulo, v.12, n.03 p.1480-1511, out./dez. 2017. MEDEIROS, F. V. G. et al. Análise da práxis docente em Biologia no ensino secundário português. Ciênc. Educ., Bauru, v. 23, n. 2, p. 341-356, 2017.

NASCIMENTO, D. M. do. Metodologia do trabalho científico: teoria e pratica. 2. ed. Belo Horizonte: Fórum, 2008.

PIMENTA, S. G. O estágio na formação de professores: unidade teoria e prática? 11. ed. São Paulo: Cortez, 2012.

PROETTI, S. Metodologia do trabalho cientifico. 5. ed. São Paulo: Edicon,2006.

RAMALHO, B. L. Formar o professor, profissionalizar o ensino: perspectivas e desafios. Porta Alegre: Sulina, 2003.

SANTOS, C. H. et al. Área de Ciências da Natureza, Matemática e suas Tecnologias. In: KUENZER, A. (org). Ensino Médio: construindo uma proposta para os que vivem do trabalho. 2. ed. São Paulo: Cortez, 2001. UNIVERSIDADE FEDERAL DO AMAPÁ/UNIFAP. Bacharelado. Projeto Político Pedagógico do Curso de Bacharelado em Ciências Biológicas. Universidade Federal do Amapá, 2014.

UNIVERSIDADE FEDERAL DO AMAPÁ/UNIFAP. Licenciatura. Projeto Político Pedagógico do Curso de Licenciatura em Ciências Biológicas. Universidade Federal do Amapá, 2008.

UNIVERSIDADE FEDERAL DO AMAZONAS/UFAM. Licenciatura e Bacharelado. Projeto Político Pedagógico do Curso de Licenciatura e Bacharelado em Ciências Biológicas. Universidade Federal do Amazonas, 2003.

UNIVERSIDADE FEDERAL DO PARÁ/UFPA, Reestruturação Curricular do Curso de Licenciatura em Ciências Biológicas. Universidade Federal do Pará, 2005.

VALLADÃO, L. A. Ensinar e Aprender a Partir Do Estágio Supervisionado: Biologia do Ensino Médio. Revista da SBEnBIO, n. 7, p. 4746-4757, out. 2014.

WEISSMANN, H. (Org.). Didática das Ciências Naturais - contribuições e reflexões. Porto Alegre: Artmed, 1998.

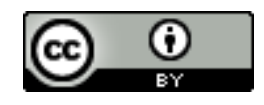

License information: This is an openaccess article distributed under the terms of the Creative Commons Attribution License, which permits unrestricted 
use, distribution, and reproduction in any medium, provided the original work is properly cited.

Artigo recebido em 04 de agosto de 2016.

Avaliado em 13 de dezembro de 2017.

Aceito em 30 de janeiro de 2018.

Publicado em 25 de maio de 2018.

\section{Como citar este artigo (ABNT):}

DAVID, Everson dos Santos; OLIVEIRA, Izabel Lucia dos Santos. A relação teoria e prática esboçada na estrutura curricular do Curso de Licenciatura em Ciências Biológicas da Universidade Federal do Amapá. Estação Científica (UNIFAP), Macapá, v. 8, n. 1, p. 31-45, jan./abr. 2018. 